\title{
Efficacy of Core Strengthening Exercise on a Geriatric Subject with Lumbar Spine Degeneration-Evidence Based Study
}

\author{
Subramanian ss* \\ Department of Orthopaedics, Chennai \\ *Corresponding author: Subramanian SS, Chennai \\ Submission: 海July 25, 2017; Published: 眥 August 21, 2017
}

\begin{abstract}
Introduction: Low back pain remains the most common cause of disability among elderly subjects leading to dependence for their daily routines physical activities. Complications and risk factors associated with spinal surgery among geriatric patients are high. Aims and objective of this original research carried on a 72 year old male with NMRI revealing multilevel degeneration of lumbar spine, where the role of obesity on lumbar degeneration and the efficacy of core strengthening and PNF were analyzed on Oswestry low back disability index.

Materials and Methodology: Advice for lumbar discectomy he was treated conservatively with specific physiotherapy techniques using core strengthening and PNF, in ten sessions from 10th May 2017 with frequency of weekly twice.

Result: Were recorded with reduction of BMI and WC $(\mathrm{P}<.05)$ and marked improvement in Oswestry low back pain index on physical functioning $(\mathrm{P}<.001)$.

Conclusion: The findings of this study can be much useful for other geriatric subjects with lumbar spine disorders.

Keywords: Low back pain; Lumbar spine disorders sciatica; Core strengthening exercises; Micro discectomy; NMRI; PNF
\end{abstract}

\section{Introduction}

Low back pain is currently the number one cause of disability in the world affects $1 / 5$ of the global population [1] and evidence shows the burden of low back pain increases from the sixth decade [2]. Low back pain in older adults is more disabling is associated with poor prognosis [3] and leads to a reduction in over all function and independence [4] low back pain can be classified based on duration of symptoms as acute (Up to 6 weeks) based on European guidelines [5] in the first three months during this period [6,7].

Low back pain is a common, costly medical condition and a major cause of pain, disability and social cost [8]. Sciatica is characterized by radiating pain in an area of the leg typically served by one nerve not in the lumbar or sacral spine and the most common cause is a herniated disc with an estimated annual incidence of sciatica in western countries 5 cases per 100 adults [9] lumbar spine disorders rank fifth among disease categories in the cost of hospital care and account for higher costs resulting from absenteeism from work and disability than any other category [10].

Variation and management of back pain is not surprising, as rates of hospitalization and surgery for low back pain vary widely by geographic region [11]. Given the frequency of the problem, the variation in its evaluation and treatment and its generally good prognosis, improving the efficiency of care for patients with low back pain is more needed [12]. This original study where the subject with low back pain and advised to undergo surgery was treated conservatively with specific exercises therapy outcome with the clinical prognosis and functional activities are evaluated and analyzed with evidence.

\section{Background information}

Mr. XXX, 72 years, gives a past medical H/O Non DM/ Non HT, mesomorph, retired as an executive with sedentary life style $\mathrm{C} / \mathrm{O}$ Low back pain of one month duration with numbness in the feet and difficulty in walking, was advised for lumbar discectomy by Neurosurgeon, but is getting treated conservatively with exercises since 10/05/17.

\section{Materials and Methodology}

O/E

i. Exagrated lumbar lord sis with obliterated cervical lord sis.

ii. Bilateral Hamstring, TendoAchilles tightness. 
iii. SLR 60 degree increases posterior thigh pain (left) and lower lumbar region

iv. Motor power left EHL 2/5, Dorsiflexors 2/5,hip abductors, extensors, knee extensors $3 / 5$

v. Vistas medial is lag was present on (Left)

vi. Tenderness at LS region (Lumbosacral)

vii. Parenthetic sensation of the feet, Toes, Great toe-drop, with dorsiflexors weakness(left), and intrinsic foot muscle sluggish but preserved arches of foot

viii. Ambulant with antalgic, scarpering gait but unaided

ix. Pain over lower lumbar and radiating up to posterior thigh and heal

X. $\quad$ BMI- $30.55 \mathrm{~kg} / \mathrm{m}^{2}$

\section{Diagnosis}

NMRI reveals lumbar spondylosis with multilevel degenerative changes mainly at L4, L5 and L5-S1 level.

\section{Treatment}
A. Core strengthening Number of sessions: 10

B. PNF Techniques Frequency: Twice Weekly

C. Home programmed was explained and subject was continuing from day one of therapy

D. Duration: 25-30 minutes

\section{Critical appraisal of his clinical prognosis}

\section{A. Reduction in the intensity of pain with each session}

B. Ambulant unaided with an improved gait for 30 minutes, left EHL (Extensor Hallucis Longus), Toes, Ankle DF (Dorsi Flexors), Motor Power 3+/5

C. Improved physical activities and daily functioning

D. Reduction in obesity $30.55 / \mathrm{m}^{2} \mathrm{~kg}$ to $28 \mathrm{~kg} / \mathrm{m}^{2}$

E. However further follow up is required on sustenance of the prognosis, where the subject was strictly advised to continue therapy with author with once a week session, regular continuous walking for 30 minutes daily and a set of home exercises.

Table 1: Table of results on Pre and Post BMI, WC and Oswestry Disability Index.

\begin{tabular}{|c|c|c|c|}
\hline Test & BMIKg/M & WCCm & Oswestry Disability Index \% \\
\hline Pre & 30.55 & 102 & 51.6 \\
\hline Post & 28 & 95 & 22 \\
\hline SD & 1.80 & 4.95 & 20.93 \\
\hline SE & 1.04 & 2.86 & 12 \\
\hline $\mathrm{t}$ & 2.45 & 2.48 & 2.75 \\
\hline P & $<.05 \mathrm{X}$ & $<.05 \mathrm{X}$ & $<.001 \mathrm{XX}$ \\
\hline
\end{tabular}

X- Significant
XX - Highly Significant

Based on further evaluation frequency of therapy to be tampered with Obesity has decreased statistically significant and Oswestry disability scale has shown highly significant with statistical analysis as shown in the Table 1.

\section{Note}

SD-standard deviation, SE-Standard Error, P-Level of significance, BMI- Body Mass Index, WC-Waist Circumference, Oswestry Disability Index-Subjective Rating Scale on 10 items related to low back physical functioning on a 5 point scale.

\section{Discussion}

Inferring from the results table the following scientific question arises and getting answered with evidence as below:

A. Can sciatica be treated with exercises? Wilco et al. [13] have recorded in a study among 141 subjects with sciatica compared conservatively treated with those who underwent micro discectomy in a one year follow up with similar recovery from sciatica. In the United States and Netherlands, the rates of surgery are relatively high, with the recommendations that if the symptoms do not improve after 6 weeks of conservative treatment options for surgery should be considered [14]. With an improved motor power of ankle and foot as stated in the clinical prognosis column, this subjects need to undergo surgery was avoided a major outcome of this study.

B. Which form of exercise to be prescribed?

C. How much a physical functional activity improves with 10 sessions (5 Weeks) of specific therapy?

Core consist of the abdominal region, hips and back including deep muscles along spine, these muscles work with legs and arms to move body in different directions while maintaining control of position and movement [15]. Studies have shown that core muscles aid in functional activities [16] and there is a clear relationship between trunk muscle activity and lower extremity movement [17]. Core strength training among elderly subjects in a 6 week study among 48 subjects with the age group of 55-70 years, thrice a week has recorded greater improvement in functional mobility [18]. A meta analysis has concluded that core strength training can increase strength by an average of $30 \%$ and balance and functional performance by $23 \%$ [19]. Gatti et al. [20] have recorded that core training can reduce disability and low back pain patients. More over the effectiveness of core training and triunes balance exercise is more easily perceived by patients than that of pain reduction methods [21].

\section{Does obesity influences lumbar spondylosis?}

Obesity is associated with musculoskeletal disorders and lows physical functioning performance [22]. Strong evidence suggests regular physical activity decreases the risk for obesity [23]. Due to progressive age decline in stature, using BMI classify may overestimate adiposity in the elderly [24] also BMI cannot make a discrepancy between fat and muscle mass [25], hence 
other parameters such as WC could be the choice of measurement [26]. Obesity influencing conservative and surgical lumbar spinal conditions in a meta analysis [27]. This study subject with marked reduction in obesity $(\mathrm{P}<.05)$ has benefited from core strengthening exercises with which he was treated during this 10 session using Physioball.

\section{Does core exercises are beneficial at geriatric subject with low back ache?}

Resistance training and ability training among 98 elderly subjects with low back ache had reduced their symptoms and improved quality of life [28], compared with typical resistance training, core strength training is easier for low back pain to learn, although it is challenging [20] and patient can practice as home exercises, adds further motivation [29]. Several studies have shown typical resistance training can easily injury low back patients [20]. Ageing is associated with physical in activity, low energy intake and loss of skeletal mass [30]. Low relative skeletal muscle mass in older persons is associated with functional impairment and physical disability [31]. Exercise interventions aimed at improving muscle strength have been identified as a key strategy for reducing fragility and maintaining functions in old age [32], and with marked reduction in pain improved physical functioning as indicated with Oswestry scale $(\mathrm{P}<.001)$ core exercises and PNF can safely be used as a major tool for geriatric subjects with lumbar spine disorders was evident.

Limitations of this original research were of a shorter duration, only obesity and subjective rating scale were used as tools of measurement. Recommendations of further studies with post physiotherapy NMRI, larger sample size of similar subjects of both sex and longer duration follow up. The author declares no financial conflict towards publication of this original research Space.

\section{Conclusion}

Conservative physiotherapy among geriatric subjects requires more attention as recorded in this research subjects chances of undergoing surgery was avoided, with in shorter time frame and specific exercises used. The outcome of this study can be used for the benefit of subjects with lumbar spine disorders of various ages.

\section{References}

1. Hoy D, March L, Brooks P, Blyth F, Woolf A, Bain C, et al. (2014) The global burden of low back pain: estimates from the Global burden of disease 2010 study. Ann Rheum Dis 73(6): 968-974.

2. Docking RE, Fleming J, Brayne C, Zhao J, Macfarlane GJ, et al. (2011) Epidemiology of back pain in older adults: prevalence and risk factors for back pain onset. Rheumatology 50(9): 1645-1653.

3. Scheele J, Luijsterburg PAJ, Bierma-Zeinstra SMA, Koes BW (2012) Chronic low back pain among older adults: A population-based perspective. J Phys Med Rehab 48: 379-86.

4. Weiner JP (2004) Prepaid group practice staffing and us. Physician supply: lessons for workforce policy. Health aff (Millwood) W4: 43-59.

5. Airaksinen O, Brox JI, Cedraschi C, Hildebrandt J, Klaber-Moffett J, et al. (2006) Chapter 4 european guidelines for the management of chronic nonspecific low back pain. Eur Spine J 15(Suppl 2): S192-300.

6. Peng HY (2012) Lin TB: Spinal pelvic-urethra reflex potentiation. Biomedicine 2: 64-67.
7. Campbell C, Scott K, Nhamo M, Nyamukapa C, Madanhire C, et al. (2013) Social capital and HIV competent communities: the role of community groups in managing hiv/aids in rural zimbabwe. AIDS Care 25(Suppl 1): S114-S122.

8. Cassidy JD, Carroll LJ, Cote P (1998) The Saskatchewan health and back pain survey. The prevalence of low back pain and related disability in Saskatchewan adults. Spine 23(17): 1860-1866.

9. Cherkin DC, Deyo RA, Loeser JD, Bush T, Waddell G, et al. (1994) An international comparison of back surgery rates. Spine 19(11): 12011206.

10.Van Tulder MW, Koes BW, Bouter LM (1995) A cost-of-illness study of back pain in The Netherlands. Pain 62(2): 233-240.

11. Ciol MA, Deyo RA, Howell E, Kreif S (1996) An assessment of surgery for spinal stenosis: time trends, geographic variations, complications, and reoperations. J Am Ger Soc 44(3): 285-290.

12. Bigos SJ, Bowyer OR, Braen GR (1994) Acute low back problems in adults. Clinical Practice Guideline 14 pp. 1-22.

13. Peul WC, Houwelingen HCV, van den hout WB, Ronald B, Eekhof JA, et al. (2007) Surgery versus Prolonged Conservative Treatment for Sciatica. N Engl J Med 356(22): 2245-2256.

14. Stam J (1996) Consensus on diagnosis and treatment of the lumbrosacral radicular syndrome. Ned Tijdschr Geneeskd 140(52): 2621-2627.

15. Braddom R (2007) Physical Medicine and Rehabilitation, (3 $3^{\text {rd }}$ edn), Elsevier Inc,

16. Willson JD, Dougherty CP, Ireland ML, Davis IM (2005) Core stability and its relationship to lower extremity function and injury. J Am Acad Orthop Surg 13(5): 316-325.

17. Chung LH, Callahan DM, Kent-Braun JA (2007) Age-related resistance to skeletal muscle fatigue is preserved during ischemia. J Appl Physiol 103(5): 1628-1635.

18. Majida NAL, Kutty NAM (2015) Randomized Controlled Trial of Core Strength Training in Older Adults: Effects on Functional Mobility. Scholars Academic Journal of Biosciences (SAJB) 3(1A): 19-25.

19. Granacher U, Lacroix A, Muehlbauer T, Roettger K, Gollhofer A, et al. (2013) Effects of core instability strength training on trunk muscle strength, spinal mobility, dynamic balance and functional mobility in older adults. Gerontology 59(2): 105-113.

20. Gatti R, Faccendini S, Tettamanti A, Barbero M, Balestri A, et al. (2011) Efficacy of trunk balance exercises for individuals with chronic low back pain: a randomized clinical trial. J Orthop Sports Phys Ther 41(8): 542 552.

21. Kawi J (2014) Self-management and self-management support on functional ablement in chronic low back pain. Pain Manag Nurs 15(1): 41-50.

22.JR, Hills AP (2006) Musculoskeletal disorders associated with obesity: a biomechanical perspective. Obes Rev 7(3): 239-250.

23. http://www.who.int/mediacentre/factsheets/fs311/en/index.html

24.Zamboni M, Mazzali G, Zoico E, Harris TB, Meigs JB, et al. (2005) Health consequences of obesity in the elderly: a review of four unresolved questions. Int J Obes 29(9): 1011-1029.

25. Inelmen EM, Sergi G, Coin A, Miotto F, Peruzza S, et al. (2003) Can obesity be a risk factor in elderly people?. Obes Rev 4(3): 147-155.

26. Ruth SM, Jean Woo (2010) Prevention of Overweight and Obesity: How Effective is the Current Public Health Approach. Int J Environ Res Public Health 7(3): 765-783.

27. Corrada MM, Kawas CH, Mozaffar F, Paganini-Hill A (2006) Association of body mass index and weight change with all-cause mortality in the elderly. Amer J Epidemiol 163(10): 938-949.

28. Liu-Ambrose, Khan KM, Eng JJ, Lord SR, Lentle B, et al. (2005) Both resistance and agility training reduce back pain and improve health- 
related quality of life in older women with low bone mass. Osteoporosis International 16(11): 1321-1329.

29. Akbari, Surabi M, Arthur R (2008) Global cooling: increasing world-wide urban albedos to offset CO2. Climatic change 95(3-4).

30. Kalyani RR, Corriere M, Ferrucci L (2014) Age-related and diseaserelated muscle loss: the effect of diabetes, obesity, and other diseases. Lancet Diabetes Endocrinol 2(10): 819-829.
31. Janssen I, Heymsfield SB, Ross R (2002) Low relative skeletal muscle mass (sarcopenia) in older persons is associated with functional impairment and physical disability. J Am Geriatr Soc 50(5): 889-896.

32.Lord SR, Menz HB, Tiedemann A (2003) A physiological profile approach to falls risk assessment and prevention. Phys Ther 83(3): 237-252. 